\title{
A Review of Human Motion Monitoring Methods using Wearable Sensors
}

\author{
https://doi.org/10.3991/ijoe.v14i10.9313 \\ Yaqing Tu( $\left.{ }^{\bowtie}\right)$, Linfeng Liu, Ming Li, Peng Chen, Yuwen Mao \\ Army Logistics University of PLA, Chongqing, China \\ yq. tu@ 163. com
}

\begin{abstract}
Human motion monitoring with wearable devices has become a hot research topic in the field of smart wearable devices. In this paper, the principles and historical development of human motion monitoring with wearable devices are analyzed and reviewed, respectively. Specifically, the current situation of human motion monitoring with wearable devices based on acceleration sensors is analyzed first. Then the existing problems and the future developing trends of research on human motion monitoring methods are summarized. Finally, the prospects of the research on of human motion monitoring method with wearable devices are discussed.
\end{abstract}

Keywords-wearable sensors, human motion state, monitoring methods

\section{Introduction}

Human motion monitoring based on acceleration sensors is a new research area. In 1953, acceleration sensors were first applied in human motion monitoring by Saunders [1]. However, acceleration sensors were not only large and heavy, but also very expensive. In recent years, with the maturing of the MEMS technology [2], the acceleration sensors have become smaller, more intelligent, cheaper, and more actively accurate in both academic research and market practical application. Ohgi [3] designed an acceleration sensor which can be worn on the wrist of a swimmer to record the athlete's "stroke" activity; Bourke et al. [4] leveraged two three-axis acceleration sensors to monitor falls and other daily human motions. The two sensors were placed on the thigh and torso to monitor the falling actions simultaneously; Boissy et al. [5] put the two-axis acceleration sensors in front and at the back of the human torso. In 2010, eZ430Chronos smart watch [6] was produced by Texas Instruments, which can collect and transfer signals of human motions wirelessly. With the help of the inner three-axis acceleration sensor, the smart watch is capable to monitor human motions by analyzing daily acceleration data. 


\section{Current status of human motion monitoring with wearable devices}

Motions of a man are affected by bones, muscles, age, physical condition, natural environment and other factors. In terms of similarity, different kinds of motions show some differences in the acceleration signals. The acceleration signals, such as the physical information, is closely related to human motions. They can always be the highprecision reactions to human activities, but different habits of human motions and different response speeds will affect the changes of acceleration. As a result, the same motion may show different data characteristics. And because the physical activity itself has high complexity, the existing technology is not able do detailed monitoring of all human motions.

In fact, due to the complexity of human motions, there is no need to perform full monitoring. We just need to study the main states of motions. Table 1 lists the types of motions that can be monitored in recent years in domestic and foreign literatures.

Open the document you would like to format and import the styles. How this works depends very much on the version of MS WORD that you use. The styles' names to be used for online-journals.org are preceded by a " 0 " which makes them appear first in the styles list and therefore easier to be found.

Table 1. The types of motion state that can be monitored in recent years in domestic and foreign literature

\begin{tabular}{|c|c|c|c|}
\hline Literature & Action category & Sensor location & $\begin{array}{c}\text { Number and type of sen- } \\
\text { sors }\end{array}$ \\
\hline Ascher et al. [7] & $\begin{array}{l}\text { Walking, sitting, standing, run- } \\
\text { ning }\end{array}$ & $\begin{array}{l}\text { Right ankle, right } \\
\text { wrist, chest }\end{array}$ & 3 three-axis accelerometer \\
\hline Guo et al. [8] & $\begin{array}{l}\text { Standing, sitting, lying, walk- } \\
\text { ing, brisk walking, }\end{array}$ & Waist, thighs & 2 three-axis accelerometer \\
\hline Fuentes et al. [9] & $\begin{array}{l}\text { Standing, walking, running, } \\
\text { falling, lying, jumping }\end{array}$ & Right hip & $\begin{array}{l}3 \text { three-axis accelerometer, } 1 \\
\text { gyroscope, } 1 \text { magnetometer }\end{array}$ \\
\hline Benjamin et al. [10] & Back, sit, stand, running & $\begin{array}{l}\text { Head, arm, waist, } \\
\text { crotch, thigh, calf, } \\
\text { ankle }\end{array}$ & $\begin{array}{l}10 \text { three-axis accelerometer, } \\
4 \text { gyroscopes }\end{array}$ \\
\hline Fuentes et al. [9] & $\begin{array}{l}\text { Walking, running, walking up, } \\
\text { walking down, sitting }\end{array}$ & waist & 1 three-axis accelerometer \\
\hline Chang et al. [11] & $\begin{array}{l}\text { Standing, sitting, lying, walk- } \\
\text { ing, upstairs, downstairs, run- } \\
\text { ning }\end{array}$ & waist & 1 three-axis accelerometer \\
\hline
\end{tabular}

\section{$3 \quad$ Principles of human motion monitoring}

At present, human motion monitoring is performed mainly with acceleration sensors worn on some parts of the body. The sensors perceive and extract the acceleration amplitudes in various parts of the body, and then determine the motion state of the body using appropriate algorithms according to the acceleration amplitudes. Figure 1 shows 
that the sensor is worn on the upper abdomen and waist of the experiment subject, respectively.

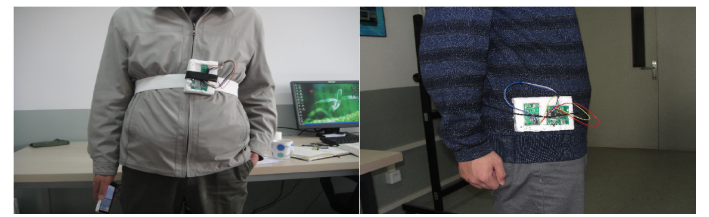

(a)

(b)

Fig. 1. (a) The sensor placed on upper abdominal (near the gravity) (b) The sensor placed on waist

The most widely used sensor is the three-axis acceleration sensor, because the threeaxis acceleration sensor can measure in three axial directions, that is, $\mathrm{X}, \mathrm{Y}$ and $\mathrm{Z}$ axes in the 3D Cartesian coordinate system. Figure 2 shows the three-dimensional coordinates of the human body acceleration. The acceleration signal obtained in each direction can be used to characterize the velocity and spatial trajectory information generated by the dynamic state of the human body over time. On the other hand, it can characterize the inclined angles of static behaviors and actions of the human body relative to the reference plane (generally referring to the reference plane of gravity acceleration). Therefore, we can use the three-axis acceleration sensor to obtain the acceleration signals of the body parts.

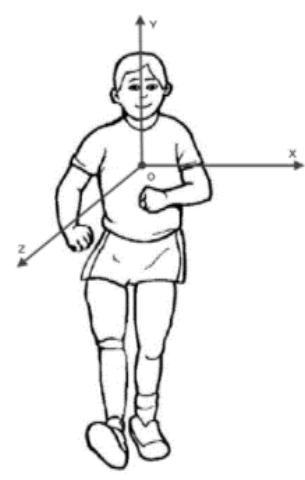

Fig. 2. The three - dimensional spatial coordinates of body acceleration

Through the three-axis acceleration sensor, we can obtain the accelerations of the human body in all directions and the acceleration signal amplitude vector sum: $\mathrm{a}_{\mathrm{SVM}}=$ $\sqrt{ }\left(\mathrm{a}_{\mathrm{xt}}^{2}+\mathrm{a}_{\mathrm{yt}}^{2}+\mathrm{a}_{\mathrm{zt}}^{2}\right)$, Using the acceleration amplitude vector and the change value in the corresponding time, through the corresponding identification algorithm to, we can determine the current motion state of movement of the human body. Human motion monitoring is performed with various sensors worn on different parts of the body. A monitoring system is mainly composed of six parts, as shown in figure 3 . 


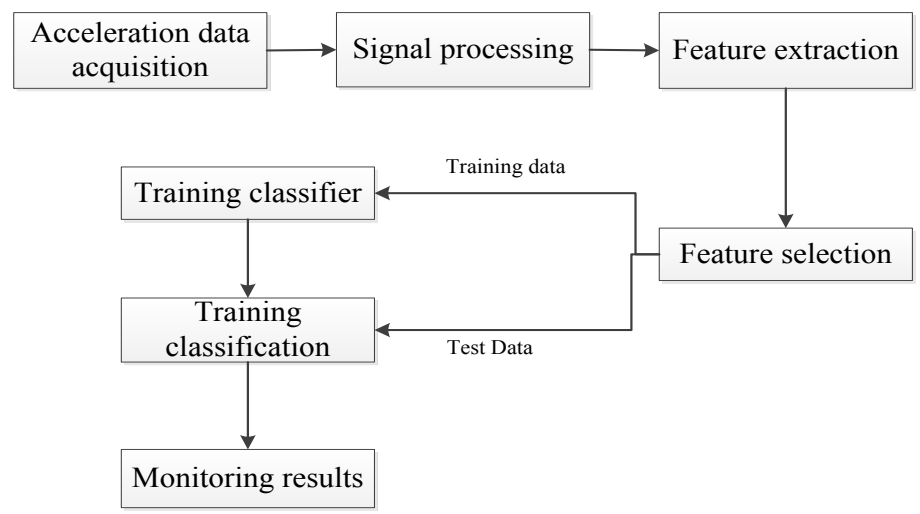

Fig. 3. The process of human motion state monitoring based on the wearable sensors

\section{$4 \quad$ Human motion monitoring methods using wearable devices}

The choice of classification methods plays an important role in the monitoring capability of the whole monitoring system. According to the principles of monitoring, the human motion monitoring methods using wearable devices can be divided into two categories: the motion monitoring method based on template matching and motion monitoring method based on statistical mode.

\subsection{Motion monitoring method based on template matching}

The general technology of motion monitoring based on template matching is the Dynamic Time Warping (DTW) method. This method is usually to calculate the similarity between the prototype calculation and the monitoring sample to obtain the most similar prototype, and then monitor the output category of the monitoring sample according to the prototype category. The advantage of this approach is that it does not require statistical training of training samples, so it would be a good choice in the absence of a large number of samples for statistical training. For example, the algorithm proposed in the literature [12] used the DTW method to monitor handwritten digits 09 in the writer-dependent and writer-independent cases. In the former case, each numeral was written 5 times to form 5 sets of samples; in the latter case, numeral data of 12 writers were collected with each numeral written for 4 times, so there were 48 sets of samples. The experimental results showed that the average recognition rate in the writer-dependent case was about $98 \%$, and that the average rate in the writer-independent case was about $90 \%$. So, the recognition performance of the DTW method is good for small sample sizes. The recognition process of the DTW algorithm is shown in the figure 4 . 


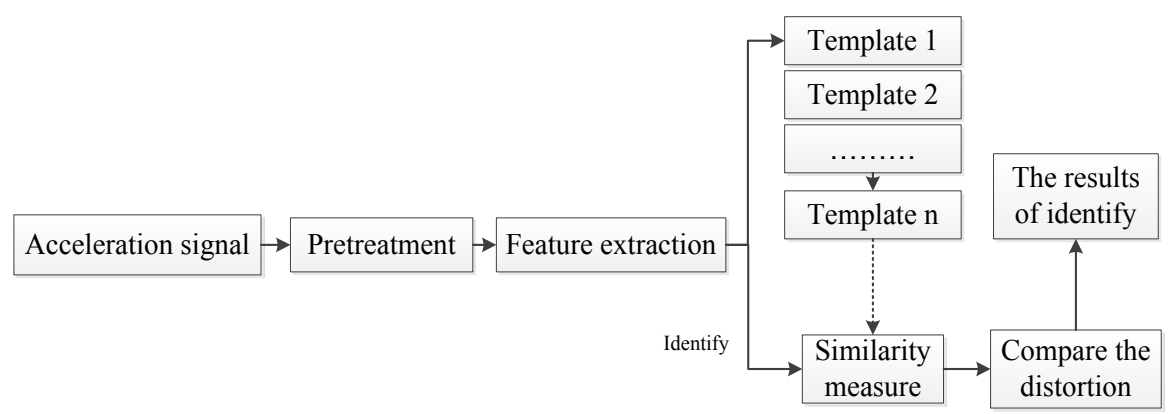

Fig. 4. The identification process of DTW algorithm

\subsection{Motion Monitoring Method based on Statistical Model}

Compared with the template matching method, the statistical model monitoring usually needs a large number of samples for statistical learning. Although it takes a lot of time and effort to collect and train the samples, the system has better robustness and higher precision. The statistical mode monitoring method is one of the most widely used monitoring methods in the field of human motion pattern monitoring based on acceleration sensor. After the selection and extraction of features, we need to select the appropriate classification method to classify the monitoring objects according to the known feature vectors. The selection of classification methods plays an important role in the whole monitoring system. There are a lot of methods to solve the classification problem, the frequently used ones of which are Decision Tree [13-14], Naive Bayesian [15-16], K-Nearest Neighbors, KNN [15], Support Vector Machine [17], Hidden Markov Model [18], Neural Network Method and so on.

Decision Tree Classification Method. The Decision Tree uses the hierarchical strategy to decompose a complex problem into a series of simple problems at different levels to solve them. Decision tree is suitable for not only the classification of discrete data, but also continuous data. In the late 1970s and early 80s, J. Ross Quinlan proposed the Decision Tree algorithm (ID3) and Leo Breiman proposed CART. Subsequently, the C4.5 algorithm [19] was proposed, which is an extension of the ID3 algorithm. In addition to the processing of the ID3 algorithm, it can also deal with discrete descriptive attributes and continuous descriptive attributes. A typical classification model of the Decision Tree Classification Method is shown in figure 5.

Naive Bayesian Classification Method. The Naive Bayesian classification method is like a generalization of HMM. Compared with HMM, it has obvious advantages in solving the problem of complex motion monitoring: HMM requires that all features should be compressed to a node. The number of required training samples increases rapidly with the increasing number of state variables (In reality, it is often difficult to collect so many training samples), and the computational complexity also increases rapidly. Haibing Ren used the Bayesian network to combine local limb movements in the process with the whole body, which improved the accuracy and robustness of human motion monitoring [20]. The recognition process of the Naive Bayesian Classification Method is shown in the figure 6 . 


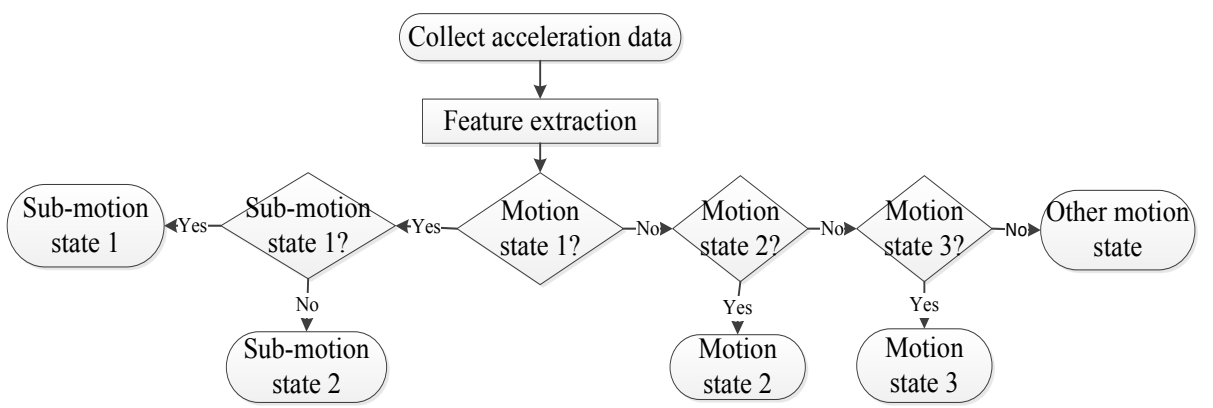

Fig. 5. A typical classification model of Decision Tree

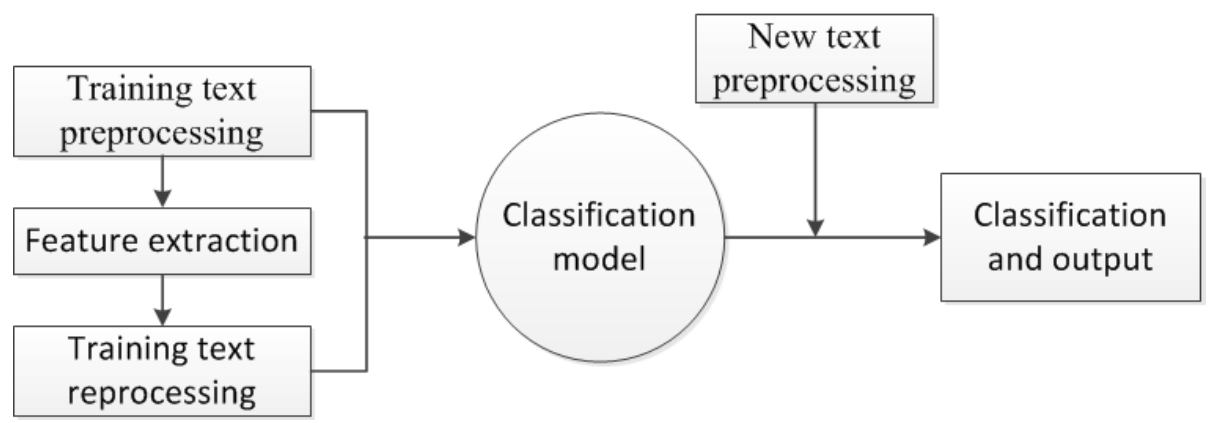

Fig. 6. The identification process of Naive Bayesian Classification Method

K-Nearest Neighbors Classification Method. The K-Nearest Neighbors is a supervision mode classification method. Figure 7 shows a typical KNN classification model. In this model, where there are $\mathrm{K}$ nearest neighbors, when $\mathrm{K}=1$, the algorithm becomes the nearest neighbor algorithm, which is to look for the nearest neighbor. So, given a training data set, for a new input instance, it finds the nearest $\mathrm{K}$ instances from the training data set (the above-mentioned $\mathrm{K}$ neighbors). The majority of these $\mathrm{K}$ instances fall within a class, so the input instance is also classified into this class.

Support Vector Machine Classification Method. The Support Vector Machine classification method is based on data mining technology. It was put forward by Vapnik based on the statistical theory and structural risk minimization principle of the classification algorithm. The biggest feature of this method is to construct an optimal hyperplane in accordance with the criteria of structural risk minimization to improve the generalization ability of the learning machine. Song et al. [21] used the integrated threeaxis acceleration sensor to collect acceleration signals generated by the daily movement of old people wearing the module, SVM can be used as the classification method to effectively monitor the 9 daily motions, with a monitoring rate of up to $96 \%$. 


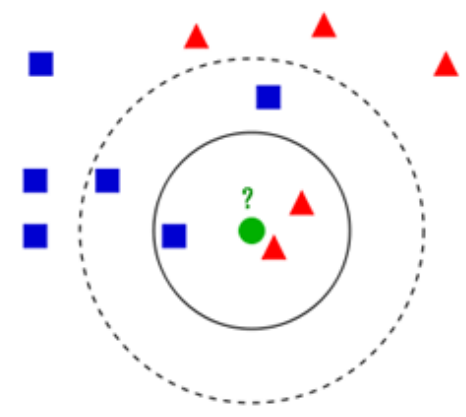

Fig. 7. A typical KNN classification model

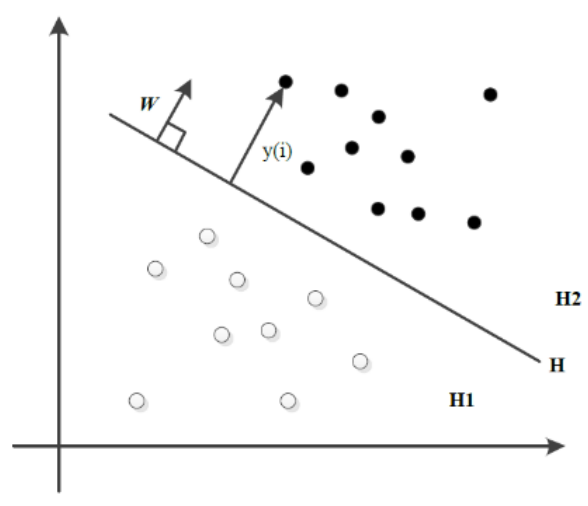

Fig. 8. A typical SVM classification interface

Figure 8 shows a typical SVM classification interface. In this figure, $y(i)=$ $w^{t} x(i)+b$, where $w$ is the normal vector of the dimension of the hyperplane, and $\mathrm{w}=[\mathrm{w} 1, \mathrm{w} 2, \ldots, \mathrm{wn}] ; \mathrm{b}$ is the intercept; $\mathrm{x}(\mathrm{i})$ is the feature of the $\mathrm{i}$-th sample; $\mathrm{y}(\mathrm{i})$ is the function interval. $\mathrm{H} 1$ and $\mathrm{H} 2$ are two different classification interfaces.

(5) Hidden Markov Mode Classification Method

The Hidden Markov Mode classification method is widely used in our everyday life. In 1990s, HMM was applied for the first time in the monitoring on the motion state by Yamato [22] to study the state of each type of training. The Baum-Welch model is used to adjust the model, and at last all kinds of motion models are generated. Finally, the monitoring results of the image sequence are calculated by the forward algorithm [23]. HMM has been widely used in the research of the motion monitoring method, and it has produced many improved algorithms. Yuan and Yu [24] used the HMM to do semi supervised learning of human motions, and transform the state of human body motions into symbolic sequences. The recognition process of the Hidden Markov Mode Classification Method is shown in the figure 9. 


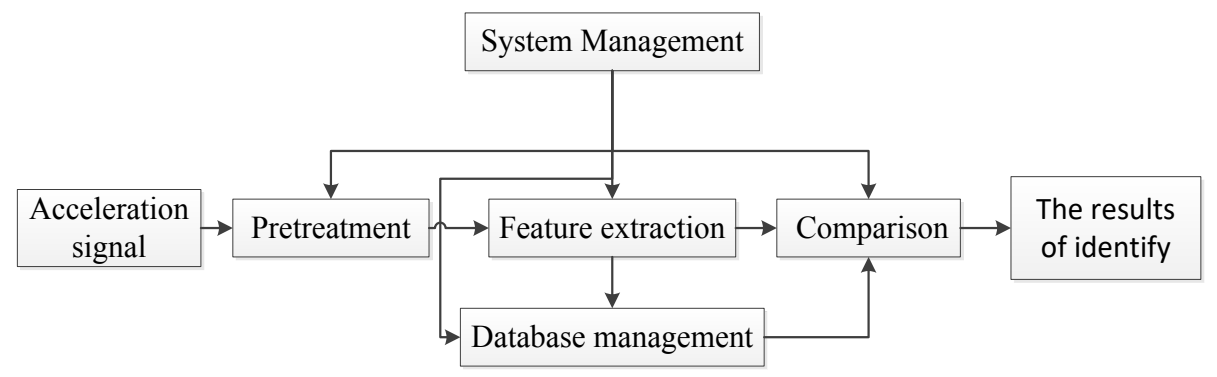

Fig. 9. The identification process of Hidden Markov Mode Classification Method

(6) Neural Network Classification Method

The Neural Network classification method is similar to the neural structure of the brain. In this classification model, the nodes are connected to each other to form a large network, which can be used to deal with the corresponding information to achieve the purpose of testing sample classification. In the training process, the weight of each network node will change with the corresponding change in the training. After training, the network will have the ability to classify the monitoring samples tested. A typical Neural Network motion discrimination model is shown in Figure 10. As can be seen, $\mathrm{x} 1, \mathrm{x} 2, \ldots, \mathrm{xn}$ are the characteristic inputs, and yi is the discriminant output.

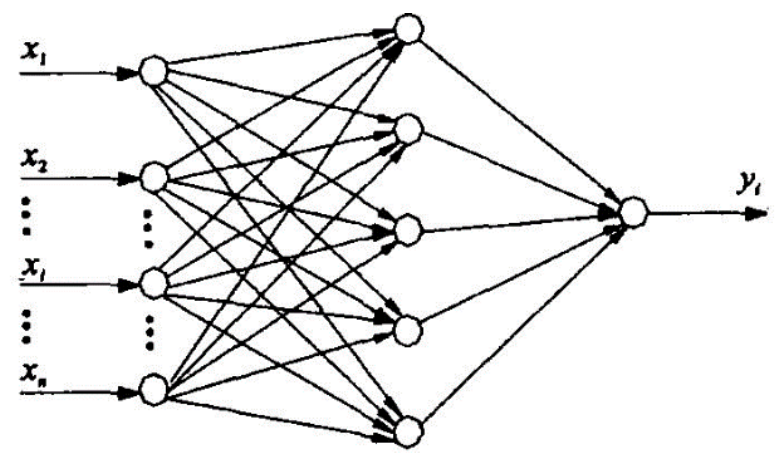

Fig. 10.A typical Neural Network motion state discrimination model

\section{Comparison of classification methods}

Various classification methods described above have their own characteristics. The researchers used the classification methods to collect data sets of monitored motions to test the performances of different monitoring algorithms, but the performances of these monitoring algorithms could not be measured. In this paper, we compare the performances of several classification methods with the same data set. Table 2 summarizes the category and number of monitoring, different motions monitored by type in the literature, placement of sensors and use of various classification methods to obtain the subject-independent action monitoring accuracy. 
Table 2. The motion monitoring performance comparison of each classification method in different literatures

\begin{tabular}{|l|l|l|l|}
\hline $\begin{array}{l}\text { Literatures, num- } \\
\text { ber of test per- } \\
\text { sons }\end{array}$ & \multicolumn{1}{|c|}{ Action category } & Sensor type and location & $\begin{array}{l}\text { Monitoring accuracy } \\
\text { by different methods }\end{array}$ \\
\hline $\begin{array}{l}\text { Literature [25] } \\
(20)\end{array}$ & $\begin{array}{l}\text { walk, run, ride, brush your teeth, } \\
\text { take the elevator, watching TV } \\
\text { and so on the upper arm, waist, } \\
\text { buttocks, 20 daily actions }\end{array}$ & $\begin{array}{l}\text { Two axis accelerometer } \\
(76.25 \mathrm{~Hz} \text { sampling rate) } \\
\text { arm, waist, hip, thigh, calf } \\
(5)\end{array}$ & $\begin{array}{l}\text { Decision Tree (84\%) } \\
\text { KNN (83\%), NB } \\
(52 \%)\end{array}$ \\
\hline $\begin{array}{l}\text { Literature [26] } \\
(12)\end{array}$ & $\begin{array}{l}\text { Lying, sitting, walking, rowing, } \\
\text { playing football, a total of 9 } \\
\text { movements }\end{array}$ & $\begin{array}{l}\text { Three axis accelerometer } \\
\text { (20Hz sampling rate) }\end{array}$ & $\begin{array}{l}\text { Decision Tree (60\%), } \\
\text { Hierarchical (83\%), } \\
\text { NN (87\%) and hips (2) }\end{array}$ \\
\hline Literature [27] (8) & $\begin{array}{l}\text { Sitting, standing, lying on the } \\
\text { side, up and down stairs, take the } \\
\text { elevator, walk, boating, playing } \\
\text { basketball, a total of 19 move- } \\
\text { ments }\end{array}$ & $\begin{array}{l}\text { Three axis accelerometer, } \\
\text { gyroscope and magnetom- } \\
\text { eter (25Hz sampling rate), } \\
\text { chest, left and right legs } \\
\text { around the wrist (5) }\end{array}$ & $\begin{array}{l}\text { Naive Bayesian } \\
(75.8 \%) \text { KNN (86.9\%), } \\
\text { SVM (87.6\%), NN } \\
(74.3 \%)\end{array}$ \\
\hline $\begin{array}{l}\text { Literature [28-29] } \\
(25)\end{array}$ & $\begin{array}{l}\text { Standing, lying on the left side, } \\
\text { lying on the right side, walking, } \\
\text { jogging, upstairs, downstairs a to- } \\
\text { tal of 8 movements }\end{array}$ & $\begin{array}{l}\text { Acceleration sensor (sam- } \\
\text { pling rate 135Hz) above } \\
\text { chest, chest, wrist, hip, } \\
\text { foot (5) }\end{array}$ & $\begin{array}{l}\text { C4.5(89\%), Naive } \\
\text { Bayesian (81\%), SVM } \\
(86 \%)\end{array}$ \\
\hline
\end{tabular}

\section{Development trend for motion monitoring methods}

Among the recent studies on motion state monitoring at home and abroad, few has been completed on the post-processing single window motion mode monitoring, but the post-processing work has a great impact on the construction of state monitoring system. A complete motion monitoring system not only focuses on the motion of an isolated window, but also summarizes motions in a certain length of time and throughout the day. Recently, in terms of the application, value and prospects of state monitoring, some products have achieved certain results, but there is still a lot of work to do to improve the accuracy and reliability of motion monitoring. At present, the research of human motion monitoring based on acceleration sensor is still in the basic stage and in terms of both research methods and hardware equipment, there is still great room for improvement. With the further development of microelectronics and sensors, hardware equipment will evolve further towards higher precision and smaller size. Sensors can now be widely applied in mobile phone devices, laptops and video game systems. Therefore, the research based on acceleration sensor will have a broader prospect.

\section{Conclusion}

In the military field, the human motion monitoring methods with wearable sensors have attracted more and more attention from all governments of the world, so there are great application prospects for human motion monitoring based on wearable sensor in military field. How to develop a wearable motion monitoring system, how to implement real-time monitoring on the motion state of individuals and how to keep control over 
the motions and body conditions of soldiers will become important topics for the national defense department. It can also be used together with other physiological parameters, external environment temperature and air pressure data to analyze the comprehensive data of individuas' daily motions. For example, in terms of heart and lung functions, the heart rate is taken into account in the daily motions together with ambient temperature, air pressure and other factors to fully evaluate individuals' physiological responses. In summary, human motion monitoring based on acceleration sensor has a very broad application prospect in intelligent human-computer interactions, intelligent monitoring, health monitoring, perception and evaluation of human motion energy consumption by handheld devices and other fields, and that is why this field has become a hot topic of research at home and abroad.

\section{Acknowledgements}

This study is supported by National Natural Science Foundation of China (NNSFC) (Grant no. 61271449, 61302175, 61601493), Key Program of Natural Science Foundation of Chongqing (Grant no. CSTC2015 jcyjBX0017), Science and technology innovation project for social undertakings and livelihood security of Chongqing(cstc2016shmszx0839) and Special Project for 100 Academic and Discipline Talents of Chongqing (Grant no. 2012-44).

\section{References}

[1] Saunders, J.B., Inman, V.T., Eberhart, H.D. (1953). The major determinants in normal and pathological gait. Journal of Bone and Joint Surgery, 35(3): 543-558. https://doi.org/10.2106/00004623-195335030-00003

[2] Wang, B. (2010). Research and design of sensor closed loop detection circuit of MEMS. Xi'an: University of Electronic and Science of Xi'an.

[3] Ohgi, F., Ichikawa, H., Miyaji, C. (2002). Microcomputer-based acceleration sensor device for swimming stroke monitoring. Jsme International Journal Series C-Mechanical Systems Machine Elements and Manufacturing, 45(4): 960-966. https://doi.org/10.1299/jsmec. $\underline{45.960}$

[4] Bourke, A.K., O'Brien, J.V., Lyons, G.M. (2007). Evaluation of a threshold-based tri-axial accelerometer fall detection algorithm. Gait and Posture, 26(2): 194-199. https://doi.org/10.1016/i.gaitpost.2006.09.012

[5] Boissy, P., Choquette, S., Hamel, M., Noury, N. (2007). User-based motion sensing and fuzzy logic for automated fall detection in older adults. Telemedicine and e-Health, 13(6): 683-694. https://doi.org/10.1089/tmj.2007.0007

[6] Ribeiro, B., Espirito, S.A., Calixto, W. (2014). Development of a low power wireless network to support elderly people based on e Z430-Chronos and Simplici TI. Proceed-ings of the 6th European Embedded Design in Education and Research, Milano, 11-15.

[7] Ascher, F., Nabil, H.C., Chieh, C., Pottie, G. (2012). Estimation of accelerometer orientation for activity recognition. Proceedings of the 34th Annual International Confer-ence of the IEEE EMBS, 2076-2079. 
[8] Guo, Y.C., He, W.H., Gao, C. (2012). Human activity recognition by fusing multiple sensor nodes in the wearable sensor systems. Journal of Mechanics in Medicine and Biology, 12(5): 1-15. https://doi.org/10.1142/S0219519412500844

[9] Fuentes, D., Gonzalez, A.L., Angulo, C. (2012). Online motion recognition using an accelerometer in a mobile device. Expert Systems with Applications, 39(3): 2461-2465. https://doi.org/10.1016/j.eswa.2011.08.098

[10] Benjamin, F., Ammar, K., Nabil, H.C., Chien, C., Pottie, G. (2012). Feature selection based on mutual information for human activity recognition. Proceedings of the IEEE International Conference on Acoustics, Speech and Signal Processing, Kyoto, 1729-1732.

[11] Chang, W.H., Shin, J.K., Nam, S.K. (2010). Implementation of hmm-based human ac-tivity recognition using single triaxial accelerometer. IEICE Transactions on Funda-mentals of Electronics, Communications and Computer Sciences, 93(7): 1379-1383.

[12] Choi, S.D., Lee, A.S., Lee, S.Y. (2006). On-line handwritten character recognition with 3D accelerometer. IEEE International Conference on Information Acquisition, Wei-hai, Shandong, China, 845-850. https://doi.org/10.1109/ICIA.2006.305842

[13] Wang, S., Yang, J., Chen, N., Chen, X. (2005). Human activity recognition with user-free accelerometers in the sensor Networks. International Conference on Neural Net-works and Brain, Beijing, 23(2): 1212-1217.

[14] Xu, Y., Ji, H., Fermuller, C. (2009). Viewpoint invariant texture description using fractal analysis. International Journal of Computer Vision, 83(1): 85-100. https://doi.org/10.1007/ s11263-009-0220-6

[15] Preece, S.J., Goulermas, J.Y., Kenney, L.P.J., Howard, D. (2009). A comparison of fea-ture extraction methods for the classification of dynamic activities from accelerometer data. IEEE Transactions on Biomedical Engineering, 56(3): 871-879. https://doi.org/10.1109/ TBME.2008.2006190

[16] Hirchoren, G.A., Attellis, C.E. (1997). On the optimal number of scales in estimation of fractal signals using wavelets and filter banks, Signal Processing, 63(1): 55-63. https://doi.org/10.1016/S0165-1684(97)00140-0

[17] Wu, J.H., Pan, Q., Zhang, D.Q., Qi, G., Li, S. (2009). Gesture recognition with a 3-D accelerometer. Ubiquitous Intelligence and Computing, 54(6): 25-38. https://doi.org/10.1007/978-3-642-02830-4 4

[18] Yeoh, W.S., Pek, I., Yong, Y.H., Chen, X. (2008). Ambulatory monitoring of human posture and walking speed using wearable accelerometer sensors. IEEE 30th Annual International Conference of Engineering in Medicine and Biology Society, 2008(5): 5184-5187.

[19] Quinlan, J.R. (1993). Programs for machine learning. San Francisco, Morgan Kaufmann publishers.

[20] Ren, H.B. (2003). Non specific human action recognition. Beijing: Tsinghua Universi-ty.

[21] Song, S.K., Jang, J., Park, S. (2008). An efficient method for activity recognition of the elderly using tilt signals of tri-axial acceleration sensor. Proceedings of 6th Interna-tional Conference on Smart Homes and Health Telematics, USA, 99-104. https://doi.org/10.1007/ 978-3-540-69916-3_12

[22] Yamato, J., Ohya, J., Ishii, K. (1992). Recognition human action in time-sequential images using hidden Markov model. Proceedings of IEEE Conference on Computer Vision and Pattern Recognition, IEEE Computer Society Press: 379-385.

[23] Tang, L., Chen, M.J. (2016). Image denoising method using the gradient matching pur-suit. Mathematical Modelling of Engineering Problems, 3(2): 53-56. https://doi.org/10.18280/ mmep.030201 
[24] Yuan, H.J., Yu, C.R. (2011). A semi supervised learning method for human behavior recognition based on Markov random walk. Journal of computer aided design and computer graphics, 23(10): 1749-1757.

[25] Lin, S., Wang, L., Huang, B., Zhang, Y.T. (2009). A pilot study on bsn-based ubiqui-tous energy expenditure monitoring. International Workshop on Wearable \& Implant-able Body Sensor Networks, 49-52.

[26] Albinali, F., Intille, S., Haskell, W. (2010). Using wearable activity type detection to improve physical activity energy expenditure estimation. Acm International Confer-ence on Ubiquitous Computing, 110(9): 311-320. https://doi.org/10.1145/1864349.1864396

[27] Wang, C.L., Zhang, S.X. (2016). Global solution and stability analysis of constant de-lay stochastic different IA equation. Advances in Modelling and Analysis A, 53(1): 17-29.

[28] Ghasemzadeh, H., Jafari, R. (2011). Coordination analysis of human movements with body sensor networks: a signal processing model to evaluate baseball swings. IEEE Sensors Journal, 11(3): 603-610. https://doi.org/10.1109/JSEN.2010.2048205

[29] Mahmoudi, A., Mejri, I. (2015). Analysis of conduction-radiation heat transfer with variable thermal conductivity and variable refractive index: application of the Lattice Boltzmann method. International Journal of Heat and Technology, 33(1): 1-8. https://doi.org/10.18280/ ijht.330101

\section{Authors}

Yaqing Tu (Corresponding author) received his B.Sc. degree in 1984 from automatic control engineering in Chengdu university of Science and Technology, M.Sc. degree in 1991 from automatic control theory and application in Chongqing University, and Ph.D. degree in 1994 from precise instrument and machinery in Chongqing University. Now he is a professor and Ph.D. supervisor in Logistical Engineering University. His main research interests include intelligent detection and instrumentation, intelligent automation system. Corresponding author's email: yq.tu@163.com.

Linfeng Liu received his B.Sc. degree in 20012 from network engineering in the University of Electronic Science and Technology of China, M.Sc. degree in 2015 from computer science and technology in the Logistics Engineering University. Now he is a doctoral student major in Military Logistics in Army Logistics University of PLA. His main research interests include logistics information and intelligent testing.

Ming Li is a lecturer of Military Logistics in Army Logistics University of PLA.

Peng Chen received his B.Sc. degree in 2014 from Chongqing University, now he is $\mathrm{Ph} . \mathrm{D}$. candidate in Army Logistics University of PLA. His main research interests include theory and technology of intelligent measurement and control.

Yuwen Mao is a lecturer of Military Logistics in Army Logistics University of PLA.

Article submitted 27 August 2018. Resubmitted 13 September 2018. Final acceptance 23 September 2018. Final version published as submitted by the authors. 